\title{
HISTOLOGY AND FUNGAL FLORA OF SHOT-HOLE BORER BEETLE (XYLEBORUS FORNICATUS) GALLERIES IN TEA (CAMELLIA SINENSIS)
}

\author{
N. S. KUMAR ${ }^{1 *}$, P. HEWAVITHARANAGE ${ }^{1}$ and N.K.B. ADIKARAM ${ }^{2}$ \\ ${ }^{1}$ Department of Chemistry, University of Peradeniya, Peradeniya. \\ 'Department of Botany, University of Peradeniya, Peradeniya
}

(Received: 07 October 1997; accepted: 04 September 1998)

\begin{abstract}
Histological and mycological studies made on the shot-hole borer beetle (Xyleborus fornicatus) galleries of tea stems at different developmental stages showed that there was dense growth and sporulation of Monacrosporium. ambrosium on the outer cell layers of the gallery surface, during the initial stages, when the beetle lives inside the galleries. The fungus forms intracellular mycelium in the xylem vessels, apparently by gaining entry through the pits. Intercellular mycelium was not observed. Histochemical tests showed the presence of tannins and lignins in some xylem and ray parenchyma cells of beetle infested stems. The tannin content was more in beetle infested stems than in healthy stems of both clones, but a significant difference was not observed in the lignin content. More tannin and globular materials, as well as lesser fungal growth were observed in the tea clone TRI 2023 (reported to be the least susceptible to attack by the shot-hole borer beetle) than in the clone 'TRI 2025 (most susceptible to attack by the beetle). There is a gradual reduction in growth of $M$. ambrosium and beginning of colonization of the old galleries by other fungal species after the beetle vacates the gallery. None of the fungi isolated from the olcler galleries is known to be involved in wood rotting of tea although the stem borer attack generally leads to wood rotting.
\end{abstract}

Keywords: Ambrosia fungus, Camellia sinensis, fungal flora, histology, Monacrosporium ambrosium, shot-hole borer galleries, tea, Xyleborus fornicatus.

\section{INTRODUCTION}

Nearly two thirds of Sri Lankan tea (Camellia sinensis var. assamica) plantations are affected by the shot-hole borer beetle (Xyleborus fornicatus) The beetle has a symbiotic relationship with the Ambrosia fungus, Monacrosporium ambrosium. ${ }^{2}$ The newly emerging; young adult female beetle carries spores of the fungus in its buccal sacs ${ }^{3}$ and inoculates them into the walls of galleries constructed by boring the tea stem. The beetle lays eggs inside the galleries and the developing larvae feed on this fungus. Therefore successful brood development of the beetle in the host plant depends on the growth of the fungus along the walls of galleries. It has been suggested that the beetle abstracts sterol from the tea 
stem via the fungus ${ }^{4}$ because the beetle is unable to synthesise the sterols essential for the production of moulting hormones.

Infestation of tea plants by the shot-hole borer beetle leads to two types of damage. ${ }^{1}$ The first type is the direct mechanical damage to primary and secondary branches. Damaged branches fracture readily and this can lead to a certain amount of crop loss. The second type of damage is the most important as it leads to wood rot. The tissues of the branches damaged by the beetle become exposed to the environment through the openings of the galleries and these could be infected by wood rotting fungi. In some cases the opening is sealed by cambial activity. ${ }^{1}$ Pruning of infected branches has been a moderately successful method of control. If pruning has not been done effectively wood rot can weaken the frame of the bush. Such tea bushes fail to recover after successive pruning cycles. ${ }^{5}$

It has been reported that only the Ambrosia fungus of $X$. dispar is found in beetle occupied galleries in stems of Amus cordata ${ }^{6}$ It has been suggested that the Ambrosia fungus may suppress and/or prevent other fungi from invading the gallery. This paper is a report of a study carried out to ascertain whether the Ambrosia fungus of $X$. fornicatus prevents the growth of other fungal species by inhibitory action. Hence the composition of fungi in a) galleries occupied by the beetle (type I), b) galleries vacated by the beetle (type II) and c) galleries which are in the primary stages of wood rot (type III) were studied. Microscopic studies were also carried out to examine histological differences of these galleries in the most susceptible (TRI 2025) and least susceptible (TRI 2023) clones.

\section{METHODS AND MATERIALS}

Plant Material : Plant material was collected from the Tea Research Institute sub station in Hantana, Kandy, Sri Lanka. The clones TRI 2025 and TRI 2023, reported to be the most susceptible and the least susceptible respectively, to attack by the Shot-hole Borer beetle, were chosen for the study. Three types of galleries were collected from both clones on the basis of the stage of gallery development. Six replicates consisting of six samples of each gallery type were used for the study.

Type I: Pencil size stems with galleries which were occupied by beetles and other stages of its life cycle. Tissues around the gallery appeared alive.

Type II: Pencil size stems with galleries which were in the intermediate stage and have been abandoned by the beetle. The beetle and other stages of its life 
cycle were not found inside the gallery. Tissues around the gallery were light brown in colour

Type III: Stems that were slightly larger than pencil size, having galleries abandoned by the beetle and dead tissues. These were in the primary stages of wood rot.

All samples were collected in clean sealed polythene bags and used for mycological studies on the same day. Some stem pieces were stored in F.A.A. (formalin $5 \mathrm{ml}$, acetic acid $5 \mathrm{ml}, 50 \%$ ethyl alcohol $90 \mathrm{ml}$ ) for microtome sectioning.

Microscopic studies of galleries: Transverse sections (10 $\mu \mathrm{m}$ thickness) were cut from pieces of tea stem preserved in F.A.A. having a) type I, type II and type III galleries and b) pencil thick healthy and beetle infested stems of the two clones using a microtome section cutter, and stained. 'The sections were examined under a light microscope and the thickness of the mycelial mass and the distance from the edge of the gallery to the cambium layer respectively in type I and type II galleries were measured using an eye piece micrometer. The average of six measurements was calculated for each reading.

Histochemical tests : Sections from fresh stems (healthy and beetle infested) of the clones TRI 2023 and TRI 2025 were examined for the accumulation of: tannins, presence of starch granules and lignification by histochemical tests. ${ }^{8}$

To test for tannins fresh sections of tissues were placed in 10\% ferric chloride containing one drop of saturated sodium carbonate solution. A blue green colour indicated the presence of tannins. ${ }^{8}$

Microtome sections were placed on a slide in a large drop of phloroglucin reagent ( $0.1 \mathrm{~g}$ phloroglucin in $10 \mathrm{ml}$ of $95 \%$ ethanol) and covered with a coverslip. Part of the solution was allowed to evaporate at room temperature and then a drop of $25 \%$ hydrochloric acid placed at the edge of the coverslip was allowed to diffuse in. The appearance of a red-violet colour indicated the presence of lignin. An alkaline aqueous solution of $0.001 \%$ methyl red was added at the edge of the cover slip and a permanent colour resembling that imparted by pholoroglucin is acquired by lignified cell walls. ${ }^{8}$ Sections were placed on drops of iodine ( $\left.\mathrm{I}_{2} / \mathrm{KI}\right)$ and observed under the microscope for the appearance of a purple-blue colour, as a test for starch granules. 
Isolation of fungi from galleries : Fungi were isolated from galleries by two methods.

Method 1. Stem pieces ( $3 \mathrm{~cm}$ in length) having gallery types I, II and III were taken separately, split longitudinally and tissues lining the galleries were scraped using a sterilized scalpel on to sterilized filter papers placed inside sterile petri dishes. The scraped material was transferred to a small screw cap bottle containing sterilized distilled water $(10 \mathrm{ml})$. The bottles were shaken thoroughly and a dilutions series $0,10^{-1} \cdot 10^{-2}, 10^{-3} \cdot 10^{-4}$ was prepared. Aliquots $(100 \mu 1)$ from each dilution were transferred separately onto the centre of a petri dish and quarter strength Cook's 2 medium $(15 \mathrm{ml})$ at $45^{\circ} \mathrm{C}$ was poured over and mixed well. Three replicate plates were prepared from each dilution and the plates were incubated at $26 \pm 2^{\circ} \mathrm{C}$ until fungal growth was visible.

Method 2. Stem pieces with gallery types I, II and III were split and the inner lining of each gallery was disturbed using a sterilized inoculating needle and then streaked on a Cook's No. 2 agar plate. The plates were incubated at room temperature for two days. Pure cultures were obtained from different colonies by transferring onto fresh agar plates. Fungal isolates were identified at the International Mycological Institute, Surrey, England.

$M$. ambrosium was initially isolated from the beetle using the following procedure: adult female beetles, collected directly from the gallery, were surface sterilized by immersing in $0.1 \% \mathrm{HgCl}_{2}$ for $1 \mathrm{~min}$. followed by three serial washings with sterilized distilled water. The beetle was thereafter placed on a petri dish containing Cook's No. 2 (quarter strength) medium and was incubated at $26 \pm 2^{\circ} \mathrm{C}$ until mycelia were visible. A pure culture was obtained by transferring mycelia from the growing colony on to fresh agar plates.

The viable fungal population density of the three different types of galleries was obtained by counting the number of colonies observed in a dilution series $\left(10^{-2}, 10^{-3}, 10^{-4}\right)$ and calculating the average number of colonies. Results were obtained from six trials. The numbers of colonies in dilutions 0 and $10^{-1}$ could not be counted because of the high density of colonies at these dilutions.

Interaction between $M$. ambrosium and fungi isolated from galleries: Mycelia] discs (6 mm diameter) from cultures of the fungi isolated from galleries were cut using a cork borer and placed separately in the centre of the Cook's 
No. 2 agar plates. Mycelial discs ( $6 \mathrm{~mm}$ diameter) similarly cut from the margin of a six day old culture of $M$. ambrosium growing on Cook's No. 2 agar were placed on four locations about $30 \mathrm{~mm}$ away from the centre of the $M$. cmbrosium. disc. The plates were incubated at $26 \pm 2^{\circ} \mathrm{C}$ and the diameter of the colony was measured daily for seven days and observations were made on the growth of the colonies of the two organisms, i.e. presence of an inhibition zone between two organisms and their growth rates. After seven days measurements were not made because there was overlapping of colonies

\section{RESULTS}

Microscopic examination of the sections taken through type I galleries revealed the presence of mycelium of $M$. ambrosium in the outer cell layers lining the surface of the gallery. The mycelial mass was thick $(212.5 \mu \mathrm{m}$ ) (Table 1), the growth was dense and numerous conidia were seen on the edge of the gallery tissue (Plate 1. a). These galleries had smaller cavities and most of the xylem tissues remained unaffected. The cambial tissues were several cell layers ( $373 \mu \mathrm{m}$, Table 1) away from the gallery. The thickness of the mycelial mass of the type II galleries ( $96.5 \mu \mathrm{m}$, Table 1 ) was less than that of the type I gallery (Plate 1. b). More cell layers in the pith and the xylem have been damaged and therefore the cambial layer was much closer to the edge of the gallery $(291.8 \mu \mathrm{m}$, Table 1 ) and the cavity. In the type III galleries the marginal cells lining the cavity lacked integrity and appeared dead (Plate 1. c). The mycelial growth was much less than the type I or type II galleries (Plate 1. c). The cambium was observed to be very close to the edge. The layer lining the cavity was dark brown in colour.

Mycelia in the ruptured cells lining the cavity had grown towards the cavity and intracellular mycelia were present in the layers of undamaged cells lining the cavity. Fungal bodies inside the pith cells and the xylem vessels were seen clearly and intercellular mycelium was not observed in these tissues. The mycelium appeared to have spread through the pits of xylem vessels lining the cavity. The conidia were found only in the hyphae projecting into the gallery and not in the intracellular mycelium. 


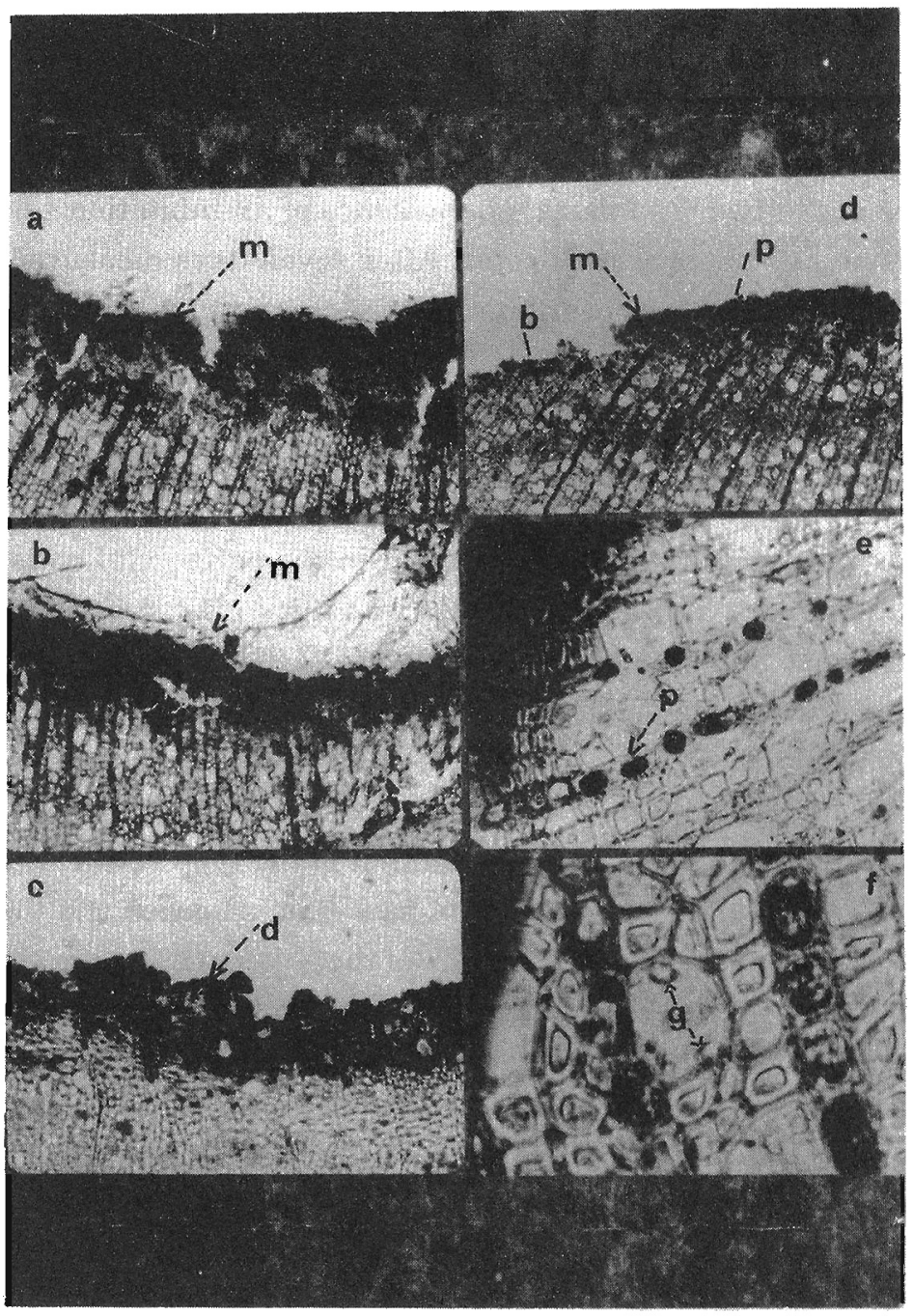

Plate 1: Transverse sections through stems from the most susceptible (TRI 2021) and the least susceptible (TRI 2023) tea clones at different stages of shot-hole borer infestation showing colonization by $M$. ambrosium and associated cytological features.

a. Type I gallery from a susceptible clone TRI 2025. (2.5 $\times 3.3)$

b. Type II gallery from a susceptible clone TRI 2025 (2.5 x 3.3)

c. Type III gallery from a susceptible clone TRI 2025 ( $2.5 \times 3.3$ )

d. Type I gallery from a resistant clone TRI $2023(2.5 \times 3.3)$

e. Ray parenchyma from TRI 2023 with brownish cell contents $(2.5 \times 3.3)$

f. Cellular globules from TRI $2023(2.5 \times 3.3)$

$\mathrm{m}=$ mycelia $\mathrm{b}=$ barrier zone $\mathrm{d}=$ dead cells; $\mathrm{p}=$ parenchyma rays with brown cell contents; $\mathrm{x}=$ xylem vessels blocked with cell deposit; $\mathrm{g}=$ globular structures 
Table 1: Mycelial mass and distance to the cambium in Shot-hole borer galleries.

\begin{tabular}{ccl}
\hline Gallery type & Thickness of mycelial mass* $(\mu \mathrm{m})$ & $\begin{array}{l}\text { Distance to the } \\
\text { cambium* }(\mu \mathrm{m})\end{array}$ \\
\hline & & \\
I & $212.5 \pm 19.4$ & $373.3 \pm 34.6$ \\
II & $96.5 \pm 11.0$ & $291.8 \pm 15.1$ \\
& $p<0.001$ & $p<0.001$ \\
\hline
\end{tabular}

Average \pm standard deviation of six replicates.

Comparison of microtome sections of stem pieces containing type I galleries with those of healthy stem showed that some vessels around the gallery were filled with a brown coloured cell content and such contents were absent inside xylem vessels of healthy stems or healthy parts of infected stems (Plate 1.d). Further the ray parenchyma in the affected stems are filled with a brown substance which was absent in ray parenchyma of healthy stems (Plate 1. d \& e).

Microtome sections of type I infested stems showed that in the bectle infested stems of the susceptible clone (TRI 2025) only a few pith cells remained intact because of the extensive colonization by the fungus, whereas in TRI 2023 more pith cell layers were present. In the susceptible clone (TRI 2025) colonization of xylem vessels by $M$. ambrosium was clearly observed. There was very little fungal growth in the xylem vessels of the least susceptible clone (TRI 2023) and the fungal growth at the edge was also restricted to only one or two layers. The vessels around the colonized region of the susceptible clone (TRI 2025) contained globular structures (Plate 1.f) which were absent in TRl 2023. There were more xylem vessels and xylem rays with dark brown contents around the galleries of the least susceptible clone than in the susceptible one. infested tis

Histochemical tests showed the accumulation of tannins in the cells at and closer to the infested stem tissues. There was more tannin in the cells of the infested TRI 2023 stems than in the infested stems of the susceptible clone (TRI 2025). The tests for lignin did not show a considerable difference between the resistant and the susceptible clones. However, there was more lignin in the xylem vessels did not acquire a blue colour when tested with iodine indicating that the globules did not contain starch. 


\section{Microflora of shot-hole borer galleries}

M. ambrosium was the only filamentous fungus found in the type I galleries where the adult beetle or stages of its life cycle were present (Table 2). In addition, yeasts and bacteria were also observed in these galleries. From the intermediate type galleries (type II), a Fusarium sp. was isolated together with $M$. ambrosium and the population of the latter was much greater (Table 3).

Table 2: Fungi found in Shot-hole borer galleries.

\begin{tabular}{|c|c|c|c|c|}
\hline \multirow{2}{*}{ Fungus } & \multicolumn{3}{|c|}{ Gallery type } & \multirow[b]{2}{*}{$\begin{array}{l}\text { Frequency } \\
(\%)\end{array}$} \\
\hline & I & II & III & \\
\hline Monacrosporium ambrosium & + & + & + & 100 \\
\hline Aspergillus niger & - & - & + & 33 \\
\hline Aurobasidium pullulans & - & - & + & 50 \\
\hline Scytalidium sp. & - & - & + & 100 \\
\hline \multicolumn{5}{|l|}{ Graphium sp.(sp. close to } \\
\hline G. putredinis) & - & - & + & 33 \\
\hline Scytalidium sp. & - & - & + & 50 \\
\hline Mucor recuorus & - & - & + & 33 \\
\hline Fusarium sp. & - & + & + & 50 \\
\hline Unidentified fungus & - & - & + & 100 \\
\hline
\end{tabular}

$:$ Frequency $\quad=\frac{\text { Number of trials in which the fungus was isolated }}{\text { Total Number of trials }} \times 100$

Seven more fungal species were isolated together with $M$. ambrosium from the type III galleries (Table 2). The fungi isolated were Aspergillus niger, Aureobasidium pullulans, Scytalidium sp., Graphium sp. (close to G. putredinis), Mucor recuorus, Fusarium sp. and another unidentified species (Table 2). The Scytalidium sp. and the unidentified species were isolated in all the trials while the frequency of isolation of other fungi was less (Table 2). Of the fungi only Graphium sp. has been reported ${ }^{9}$ as a plant pathogen and this fungus together with Scytalidium sp., $M$. recuorus and $A$. pullulans have not been reported in 
Sri Lanka previously. Other fungi are either soil inhabitants or saprophytes on. decaying plant material. The population of $M$. ambrosium was much less in the type III galleries than in the type I or type II galleries (Table 3).

Table 3: Viable density of fungi in different types of shot-hole borer galleries.

\begin{tabular}{clllllll}
\hline \multirow{2}{*}{ Type of gallery } & \multicolumn{1}{c}{ Fungus } & \multicolumn{8}{c}{ Average number of colonies } \\
& \multirow{2}{*}{ II } & 1 & 2 & 3 & 4 & 5 & 6 \\
\hline \multirow{3}{*}{ III } & M. ambrosium & \multicolumn{1}{c}{ Numerous colonies in all six trials } \\
& M. ambrosium & \multicolumn{1}{c}{ Numerous colonies in all six trials } \\
& Fusarium sp. & 4 & 12 & - & - & - & 5 \\
& M. ambrosium & 26 & 19 & 15 & 11 & 28 & 30 \\
& N. niger & 16 & - & 10 & - & - & - \\
& A. pullulans & - & 5 & 8 & - & 10 & - \\
& Scytalidium & 17 & 22 & 15 & - & 8 & 27 \\
& Graphium & 3 & - & - & 4 & - & 2 \\
& M. recuorus & - & 2 & - & - & 2 & 4 \\
& Fusarium sp. & 11 & 6 & 8 & - & - & - \\
& Unidentified fungus & 7 & 12 & 3 & 7 & 13 & 16 \\
\hline
\end{tabular}

\section{Interaction between M. ambrosium and other fungi}

M. ambrosium was grown together with each of the above isolates obtained from the galleries in separate plates of Cook's No. 2 agar and colony growth. was measured. The average diameters of the colonies are given in Table 4. The presence of $M$. ambrosium apparently does not either in.hibit or accelerate the growth of any of the six identified isolates under these conditions. Similarly none of these isolates could inhibit, in vitro, the growth of M. ambrosium colonies. However, colonies of $M$. ambrosium showed more rapid and luxurious growth in the medium than all the other isolates and often overgrew the other showing that $M$. ambrosium is able to grow competitively, in vitro, with the other isolates. 
Table 4: Diameter of the fungal colonies (M. ambrosium vs other fungi after five days incubation).

\begin{tabular}{cc}
\hline $\begin{array}{c}\text { Diameter of } \boldsymbol{M} \text {. ambrosium colony } \\
(\mathbf{m m})\end{array}$ & $\begin{array}{l}\text { Diameter of fungal } \\
\text { colony * (mm) }\end{array}$ \\
25.25 & $15.00^{1}$ \\
24.00 & $16.25^{2}$ \\
25.50 & $18.26^{3}$ \\
24.25 & $14.00^{4}$ \\
23.75 & $22.50^{5}$ \\
25.25 & $12.50^{6}$ \\
\hline
\end{tabular}

A. niger: ${ }^{2}$ A. pullulans. "Scyalidium sp." Graphium sp. ${ }^{5}$ Fuscrimm sp. "M. recuorms.

\section{DISCUSSION}

The newly formed shot-hole borer galleries (type I) in tea stems have smaller cavities and more undamaged tissue. The fungus seems to be able to colonize the galleries without causing much tissue destruction, a feature exhibited by symbiotic and specialized parasitic fungi.

There was reduced growth and sporulation of $M$. ambrosium after the gallery was abandoned by the beetle (type II) and before colonization by other fungi. More dead tissues were observed inside the type III galleries. This may have provided an environment conducive for the colonization of the galleries by saprophytic fungi. Eight fungal species were isolated from the surface scrapings of the type III galleries which had been vacated by the beetle. Most of these have been previously described as saprophytes or weak parasites. ${ }^{9-11}$

The present study suggests that $M$. ambrosium is able to grow competitively with all these fungal species in vitro. It is possible that its rapid growth in type I galleries may suppress the growth of other fungi. However in vitro conditions on agar plates cannot be directly related to the conditions found in tea stems.

It has been reported that the beetle has the ability to collect spores of $M$. ambrosium from a mixture of spores. ${ }^{3}$ Thus the beetle probably brings 
only spores of $M$. ambrosium into freshly constructed galleries. Further the mother beetle was found frequently physically blocking the entrance to the gallery. ${ }^{12}$ This may hel.p to reduce contamination of the gallery while the beetle is within the gallery. Contaminant fungi were found in the gallery together with $M$. a mbrosium when the beetle vacated the gallery or was dead inside it. Hence the live beetle probably prevents the growth of other fungi. It is also likely that Type I galleries may not provide adequate organic matter for saprophytic growth.

A frequent and important consequence of shot-hole borer infestation in tea is the wood rotting which results from colonization of exposed galleries by several wood rotting fungi. ${ }^{5}$ Wood rotting fungi were expected to be present in the Type III galleries as they were in the primary stage of wood rot. None of the fungi isolated from the Type III galleries, however, have earlier been implicated in wood rotting of tea. It is possible that the wood rotting fungi colonize diseased stems at a later stage. Forty eight fungi have been reported from Camellia sinensis theae. Hypoxylon serpens, Macrophoma and Botryodiplodia theobromae ${ }^{1: 3}$ have been recorded previously in Sri Lankan tea plantations as involved in wood rotting. ${ }^{14}$

Plants respond to infection by pathogens in numerous ways. Defence strategies against fungal infections may be adopted and these include lignification and suberization of cell walls, formation of tyloses and gum plugs, and accumulation of antifungal substances associated with fungal infections. ${ }^{15,16}$ Antifungal substances include several classes of chemical compounds such as phenolics, alkaloids, terpenoids, steroids and glycosides. We have shown earlier that caffeine, the major antifungal compound in tea stems, increases in concentration after shothole borer infestation. Further, in vitro experiments showed that caffeine, at certain concentrations, was able to completely inhibit the growth of $M$. ambrosium ${ }^{17}$

A number of cytological changes were observed to have taken place in tea stems after shot-hole borer infestation and associated fungal colonization of the galleries in tea stems. The changes were more evident in the resistant clone. The most striking change was the presence of brown coloured cell contents in the xylem and in ray parenchyma. Histochemical studies indicated the presence of tannins and the amount of tannin was observed to be more in the least susceptible TRI 2023 clone than in the susceptible one (TRI 2025). Accumulation of tannins has often been reported from infected plants and tannins are known to exhibit antifungal activity. ${ }^{1 \%}$ 
There was also evidence for lignification of the infected tissue. The production of lignin by infected host cells is another common response of plants to fungal attack. Lignin is a complex polyphenolic polymer which is both mechanically strong and resistant to enzymatic degradation. ${ }^{15}$ Accumulation of tannins, lignification and other cytological changes may be defence responses against shot-hole borer infestation and associated growth of $M$. ambrosium in the stem tissues around the galleries. This may well be the reason for restricted colonization by $M$. ambrosium of the inner cell layers in the gallery tissues of the least susceptible clone TRI 2023.

\section{Ackowledgement}

The authors thank the Tea Research Institute (TRI), Talawakelle, and the TRI :sub-station at Hantane for cooperation, the Council for Agricultural Research Policy, Sri Lanka and the Swedish Agency for Research Cooperation (SAREC) for research grants.

\section{References}

1. Sivapalan P. (1976). Final Report on Research conducted under a Grant Authorized by U.S. Public Law 480. 11.

2. Gadd C.H. \& Loos C.A. (1947). The Ambrosia fungus of Xyleborus fornicatus Eichh. Transactions of the British Mycological Society 31: 13-18.

3. Fernando E.F.W. (1960). Storage and transmission of Ambrosia fungus in the adult Xyleborus fornicatus Eichh. Coleoptera, Scolytidae. Annals and Magazine of Natural History Series 13 (2): 475-480.

4. Wickramasinghe R.L. (1978). Monographs on tea production in Sri Lanka. 7: 39-42.

5. Sivapalan P. (1985). An integrated management strategy to minimize the economic damage to mature tea caused by shot-hole borer beetle (Xyleborus fornicatus Eichh) Tea Science 54: 4-10.

6. Leach J.G. (1940). The instruction of plants and insects. In : Insect Transmission of Plant Diseases. McGraw-Hill Book Inc., 59-67. 
7. Gur E. (1965). The rational use of dyes. In : Biology and general staining methods. Garampion Press Ltd., 277

8. Johanson D.A. (1940). Plant microtechniques. McGraw-Hill Book Co., Inc. 183193.

9. Barnett H.L. \& Hunter B.B. (1972). Illustrated genera of imperfect fungi $3: 270$.

10. Hoog G.S. \& Hermanides Nijhot E.J. (1977). The black yeasts and allied hypomycetes. Studies in Mycology 3: ,270.

11. Sigler L. \& Carmichael J.W. (1976). Taxonomy of Malbranchea and some other Hypomycetes with Anthroconidia. Mycotaxon 4: 349-488.

12. Hewavitharanage P. (1997). Chemical and microbial interactions in shothole borer infestation of tea. M.Phil. Thesis, University of Peradeniya, Sri Lanka.

13. Petch T. (1923). The Diseases of the tea bush, Macmillan and Co. London 220 .

14. Coomaraswamy U. (1979). A Handbook to the fungi parasitic on the plants of Sri Lanka. National Science Council of Sri Lanka, Colombo. UNESCO: Man and the Biosphere National Committee for Sri Lanka, Publication No.4.

15. Ride J.P. (1983). Cell walls and other structural barriers in defence. In : Biochemical Plant Pathology (Ed. J.A. Callow) John Wiley and Sons Ltd, . 215-233.

16. Beckman C. H. \& Talboys P. W. (1981). Anatomy of resistance in fungal diseases of plants. (Eds. M.E. Mace, A.A. Bell, \& C.H. Beckman) Academic Press, London. 487-521.

17. Kumar N.S., Hewavitharanage P. \& Adikaram N.K.B. (1995). Attack on tea by Xyleborus fornicatus: inhibition of the symbiote Monacrosporium ambrosium by caffeine. Phytochemistry 40 (4): 1113-1116.

18. Rubin B.A. \& Arisikhovskaya Y.V. (1963). Biochemistry and physiology of plant immunity (Ed. Ollis Griffitirs) Pergamon Press Ltd 192. 